\title{
Maintenance of Electric and Hybrid Vehicles
}

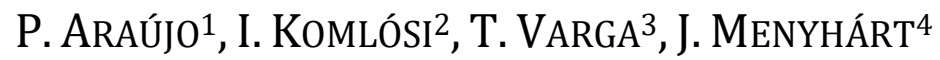 \\ 1University of Debrecen, Faculty of Engineering, Department of Mechanical Engineering, paulovictor.sa@mailbox.unideb.hu \\ 2Óbuda University, Donát Bánki Faculty of Mechanical and Safety Engineering, Department of Mechatronics, \\ komlosisti@gmail.com \\ 3University of Debrecen, Faculty of Engineering, Department of Mechatronics, tamas.varga@eng.unideb.hu \\ 4University of Debrecen, Faculty of Engineering, Department of Air- and Road Vehicles, jozsef.menyhart@eng.unideb.hu
}

An electric car is a vehicle powered by one or more electric engines, utilizing energy stored within batteries that are rechargeable. The first register of a usable electrical vehicle dates from 1880s. A hybrid vehicle incorporates two or more different power types, including, e.g., gasoline engines and electric motor. The goal in this work is to present the overall overview of the structure of the electric, hybrid and electric-hybrid vehicles, advantages and disadvantages of these types, the main points to focus when maintaining these and the challenges involved in its production and maintenance.

Keywords: Electric, maintenance, vehicle

\section{Introduction}

Automobiles are a fundamental a part of our normal lives. Yet traditional cars are one of the major responsible of urban pollution in the twenty first century. The world is currently, and will in the end, come across an acute energy problem: if one does not recognize the opportunity that electricity sources and transportation modes offer. Current environmental issues push the international community towards creating low-emission (hybrid electric) and zero-emission (electric) automobiles to substitute petrol engine vehicles [1]. People have come to recognize that vehicles can be operated not only by an internal combustion engine (using gasoline, diesel or gas), but also by an electric motor over the past 10-15 years. Such hybrid electric vehicles (HEVs) allow fuel consumption to be reduced in urban driving and pollution to be reduced, but that is only the beginning step on a rough road that will hopefully lead towards zero-emission battery electric vehicles (BEVs) enabling long-range driving. [2]

\section{History}

BEVs have the longest history of any of the advanced EV forms. BEVs date back to the late 1800s. The past of EVs is impressive. It involves the uprising of EVs following the discovery of electricity and the means of processing of electromechanical energy and then it being surpassed by gas-powered vehicles afterwards. People strayed from the ecofriendly means of transport in the early years given the lack of infrastructure, but nowadays they are once again towards the right route [1]. 
In the 1980s and 1990s numerous manufacturers launched a new series of automobiles. In addition to the launch of vehicles such as the General Motors EV-1, the Toyota RAV4-EV and the Ford Ranger EV a collection of impact analyses on battery EV was performed to evaluate the economic prospects of these vehicles as they should grow further and achieve higher production volumes. [2]

\subsection{Recent EVs and HEVs}

Almost all the major brands of automobiles have production EVs, most of which are commercially available or leased to the public. Although the condition of such vehicle systems evolves rapidly, car manufacturers often halt (their) production due to the low current market demand of those vehicles. [2]

\section{Concept and Definitions}

First, it is very important to explain the idea behind an EV and a HEV, their core concepts are describing below. However, it is necessary to understand other common descriptions that are correlated to this segment, these are presented in the Table 1. [3] for a better understanding of the usual nomenclature.

\begin{tabular}{|l|l|}
\hline $\begin{array}{l}\text { Electric Vehicle/Car (EV), } \\
\text { Electrically Chargeable } \\
\text { Vehicle/Car }\end{array}$ & $\begin{array}{l}\text { Generic terms for a vehicle powered, in part or in full, by a battery } \\
\text { that can be plugged into the mains }\end{array}$ \\
\hline $\begin{array}{l}\text { Pure-EV, Pure-Electric Car, All } \\
\text { Electric, Battery Electric Vehicle } \\
\text { (BEV), Fully Electric }\end{array}$ & $\begin{array}{l}\text { A vehicle powered only by a battery charged from mains } \\
\text { electricity. Currently, typical pure-electric cars have a range of } \\
\text { about } 100 \text { miles }\end{array}$ \\
\hline $\begin{array}{l}\text { Plug-In Hybrid Electric Vehicle } \\
\text { (PHEV), Plug-In Hybrid Vehicle } \\
\text { (PHV) }\end{array}$ & $\begin{array}{l}\text { A vehicle with a plug-in battery and an internal combustion } \\
\text { engine (ICE). Typical PHEVs will have a pure-electric range of 10- } \\
\text { 30 miles. After the pure-electric range is used up the vehicle } \\
\text { reverts to the benefits of full hybrid capability }\end{array}$ \\
\hline $\begin{array}{l}\text { Extended-Range Electric } \\
\text { Vehicle } \\
\text { (E-REV), Range-Extended } \\
\text { Electric } \\
\text { Vehicle (RE-EV) }\end{array}$ & $\begin{array}{l}\text { A vehicle powered by a battery with an ICE-powered generator } \\
\text { on board. E-REVs are like pure-EVs but with a shorter battery } \\
\text { range of around 50 miles. Range is extended by an on-board } \\
\text { generator providing additional miles of mobility In the case of an } \\
\text { E-REV the vehicle is always electrically driven and is known as a } \\
\text { series hybrid (more on this later) }\end{array}$ \\
\hline $\begin{array}{l}\text { Hybrid Electric Vehicles (HEV), } \\
\text { Full/Normal/Parallel/Standard } \\
\text { hybrid }\end{array}$ & $\begin{array}{l}\text { A hybrid vehicle is powered by a battery and/or an ICE. The } \\
\text { power source is selected automatically by the vehicle depending } \\
\text { on speed, engine load and on battery charge. This battery cannot } \\
\text { be plugged in, so charge is maintained by regenerative braking } \\
\text { supplemented by ICE-generated power }\end{array}$ \\
\hline Mild Hybrid & $\begin{array}{l}\text { A mild hybrid vehicle cannot be plugged in or be driven solely on } \\
\text { battery power. However, it does harvest power during } \\
\text { regenerative braking and uses this during acceleration (current } \\
\text { F1 cars are a type of mild hybrid) }\end{array}$ \\
\hline
\end{tabular}




\begin{tabular}{|l|l|}
\hline Micro Hybrid & $\begin{array}{l}\text { A micro hybrid normally employs a stop-start system and } \\
\text { regenerative braking which charges the 12-V battery }\end{array}$ \\
\hline Stop-start Hybrid & $\begin{array}{l}\text { A stop-start system shuts off the engine when the vehicle is } \\
\text { stationary. An enhanced starter motor is used to support the } \\
\text { increased number of engines starts }\end{array}$ \\
\hline
\end{tabular}

Table 1. Summary of EVs and HEVs and their alternative names [3]

\subsection{Electric Vehicles (EV)}

EVs are driven solely by their rechargeable batteries and electric propulsion engines. Their batteries are fueled from the power grid network in domestical homes in the evening, at workplaces throughout business hours, and at drive-in charging stations which use grid-connected chargers that are publicly or privately operated. The main advantage correlated with EVs is their exceptional performance relative to ICEs (Internal Combustion Engine) or even hybridized vehicles. Electric motors can be produced to run at efficiency levels above $90 \%$ compared to less than $30 \%$ for ICEs. A second advantage related to Evs is their low operating cost during their lifetime (lifespan) partially due to lower energy prices. [4].

\subsection{Hybrid Electric Vehicles}

In HEVs the electric motor(s) are powered by a battery. The cell is capable of charging by regenerative braking, which is a realistic method that can be implemented in urban environments where cars regularly start and stop [4], [5].

The fact that an electric motor can also function as a generator takes advantage of regenerative braking. In this case, when a driver uses the brakes, the electric motor converts into a generator to translate the forward momentum of the vehicle into energy (HEVs often use standard friction brakes in conjunction with regenerative braking) [4].

A HEV set, as shown on Fig.1, possesses an electromechanical combination for its power source.

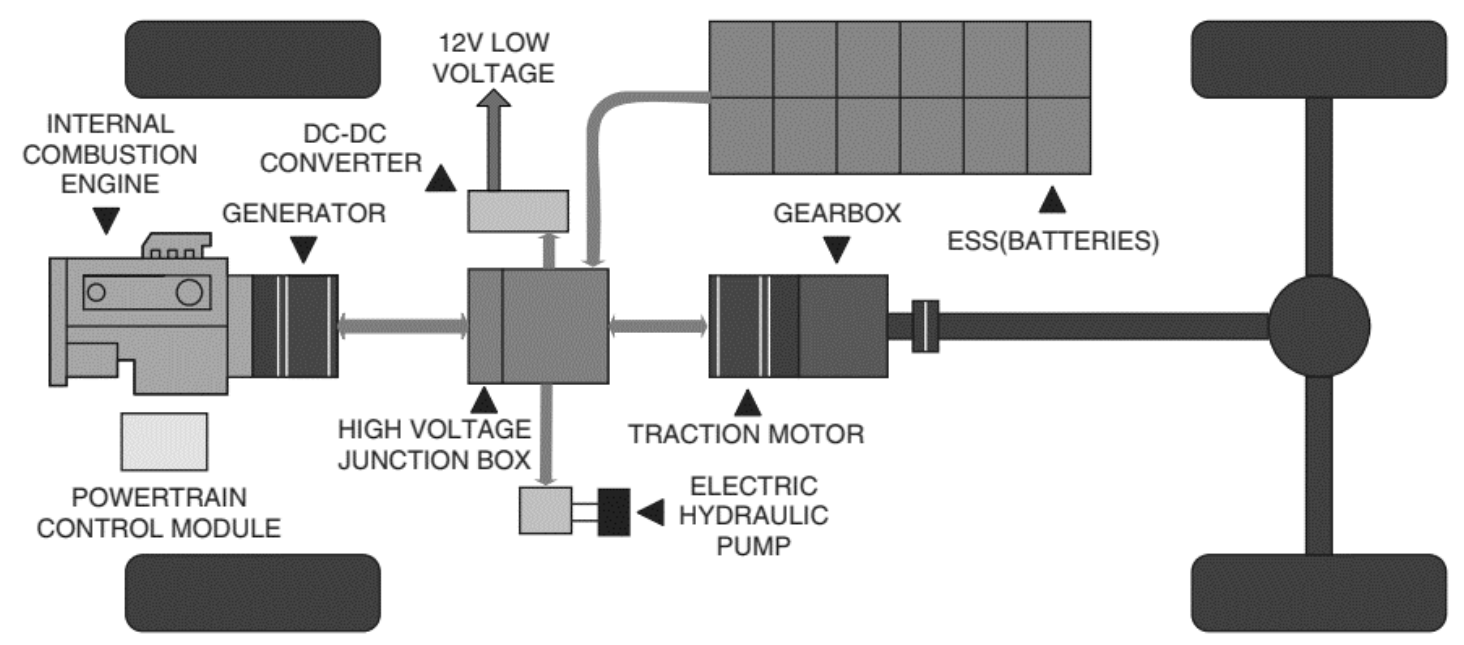

Figure 1. Rear-wheel-drive series hybrid electric vehicle layout [5] 
The electric powertrain only supplies the drive wheels with propulsion power and an engine-generator pair unit (Genset) regenerates power to the energy storage system (ESS) that supports the electrical powertrain with energy. Furthermore, broadly speaking a hybrid vehicle is an electric car with a Genset to provide electrical power when there is insufficient energy in the vehicle's battery to drive it [5].

\section{General safety precautions}

Safe working procedures are important in regards to all vehicle systems, for your protection as well as others. It is even more necessary to learn what you can do while operating on high-voltage devices. Nevertheless, in order to be safe, you one only need to obey two laws: use your common sense - don't act in haze and seek assistance if in doubt. The following section lists several specific risks along with recommendations for mitigating them while dealing with electricity or electrical systems. This is called risk assessment, which by definition is: a structured process for assessing the potential hazards that an action or activity may include.

\subsection{Safety in EVs and HEVs}

Electric vehicles (pure or hybrid) use high-voltage cells so that in a very short time energy can be transferred to a drive motor or recycled to a battery pack. For instance, the Honda Insight device uses a $144-\mathrm{V}$ battery module for regenerated energy storage. Originally the Toyota Prius used a 273.6- $\mathrm{V}$ battery pack but this was modified to a $201.6-\mathrm{V}$ pack in $2004.300 \mathrm{~V}$ voltages are already normal and others go up to $700 \mathrm{~V}$, and when one deals with these vehicles there are obviously electrical safety concerns.

EV batteries and engines have extreme electrical and magnetic potential which, if not treated correctly, can seriously injure or cause death It is very important that you take note of all the alerts and suggested safety measures provided by the safety document from the manufacturer. Figure 2 shows a battery pack of an EV, if not handled properly presents serious risk.

The safety analysis of the electronic vehicle and its control systems such as engine control, powertrain control, electrical generators control systems, AC and DC bus regulation systems, etc. require to deeply involve CAD techniques which were introduced in [6] and in [7]. These books although can be applied very effectively and successfully in systems hazard and risk analysis. 


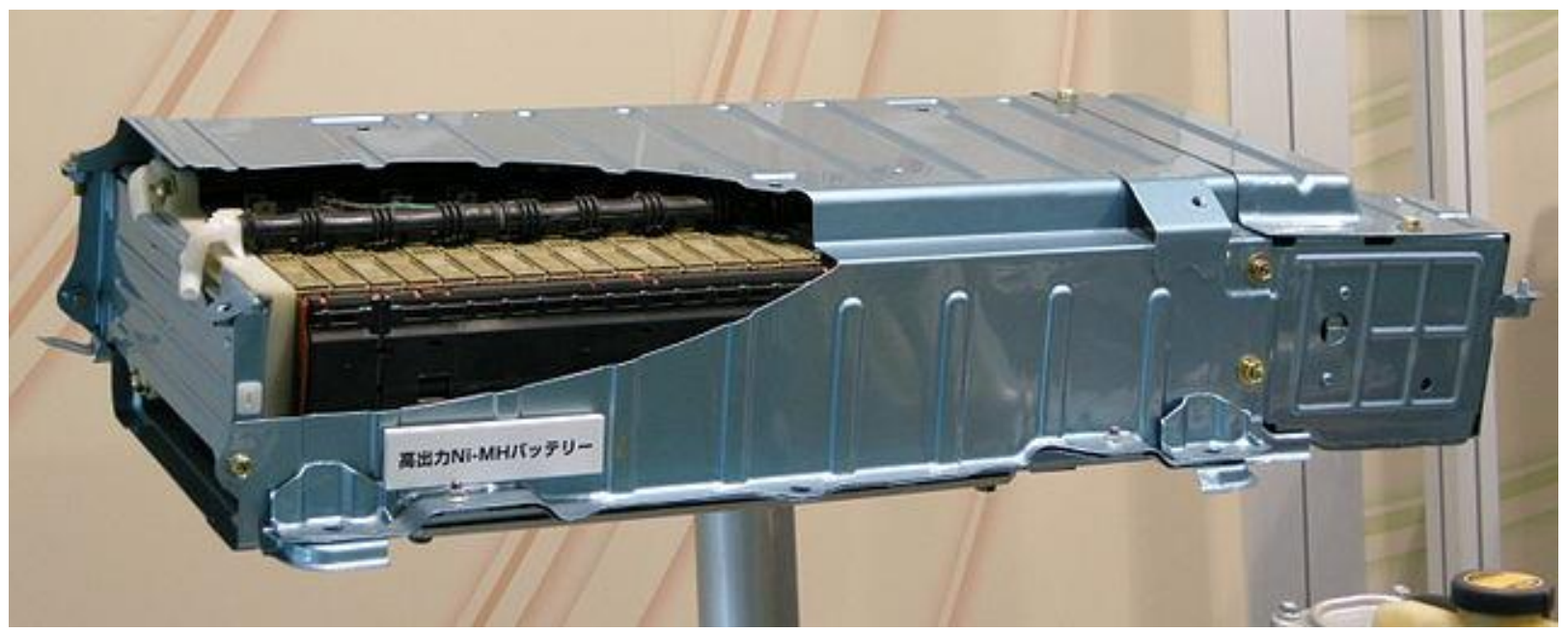

Figure 2. High-voltage battery pack [8]

\section{Maintenance, Repairs and Replacement}

It is advised and is necessary to be instructed or monitored by a professional individual before carrying out any concrete work on an EV. Always refer to manufacturer's manual for a safe work and check the required PPE for the procedures as well as set the vehicle in a safe mode before starting any operation. The following statements are the main aspects of practical work on EVs (and of all other vehicles regarding this aspect): Observe for hazards and safety; use the correct PPE; apply the correct tools and equipment; follow the instruction in the guide and the necessary workplace procedures; referral to manufacturer-specific information only [3]. Following, an overview of the maintenance steps will be shown.

\subsection{Technical Information and Data}

A variety of sources for professionals is known to exist as well as other information regarding EV vehicle, but the primary one is the manufacturers data. These are the most reliable and precise ones, that include important safety data sheets and maintenance manuals for EVs. An example of a manufacturer's data on component location is shown in the following Figure 3 [3]. The components are: 1, three-phase current drive (electric drive motor, drive motor temperature sender); 2, high-voltage battery charging socket; 3 , electrical air conditioner compressor; 4, combustion engine; 5 , battery regulation control unit; 6 , highvoltage battery; 7 , high-voltage cables; 8 , high-voltage heater (PTC); 9, power and control electronics for electric drive (control unit for electric drive, intermediate circuit capacitor, voltage converter, DC/AC converter for drive motor); 10, charging unit 1 for high-voltage battery (Source: Volkswagen Group). 


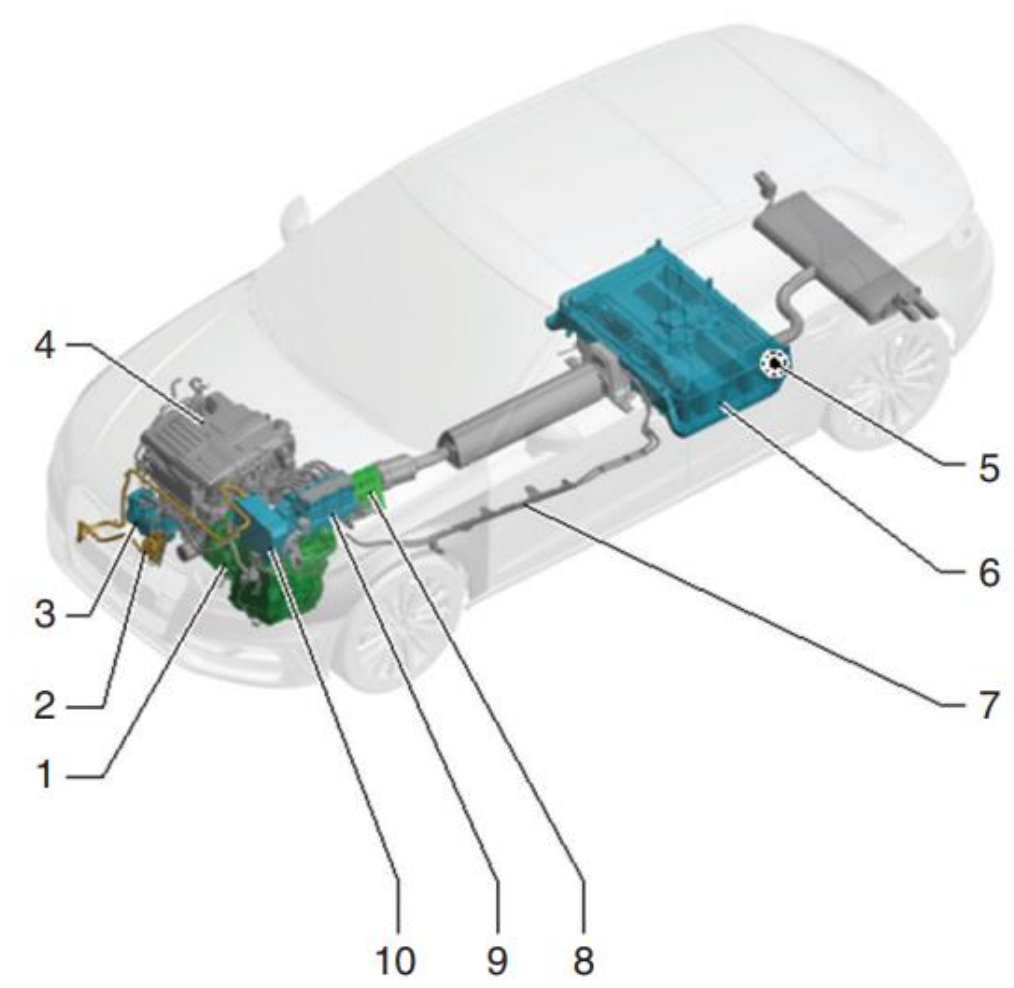

Figure 3. Components on a Golf GTE [Source: Volkswagen Group] [3]

\subsubsection{De-energizing}

Major manufacturers provide different methods of de-energizing the high-voltage system - for this procedure you need to refer to precise details of your model and your manufacturer. Following a clear example of a de-energizing procedure is provided on a model year $2015 \mathrm{VW}$ vehicle:

1 Park the vehicle securely. 2 Connect diagnostic tester. 3 Select Diagnosis mode and start diagnosis. 4 Select Test plan tab. 5 Push Select own test button and select the following menu items one after the other: Body/Electrical system. Self-diagnosis compatible systems. Electric drive control unit. Electric drive control unit, functions. De-energize high-voltage system [3].

After these steps, during this procedure phase, you will need to pull out the maintenance connector for the high-voltage module. It is an electrical connecting point between the contactors and the high-voltage battery. This is your reference for the maintenance when working with HV network.

While working on the HV it must be disabled. Last actions are to: Make sure the device is de-energized and is stable to avoid reactivation by use of a padlock; lock the high-voltage battery, put in a separated place the ignition key and the padlock key; add appropriate warning signs where applicable; Check for: fault codes; driver view warning module information; and if the warning signs are in place, too [3]. Figure 4 helps to illustrate this procedure for a better understanding of the instructions. 

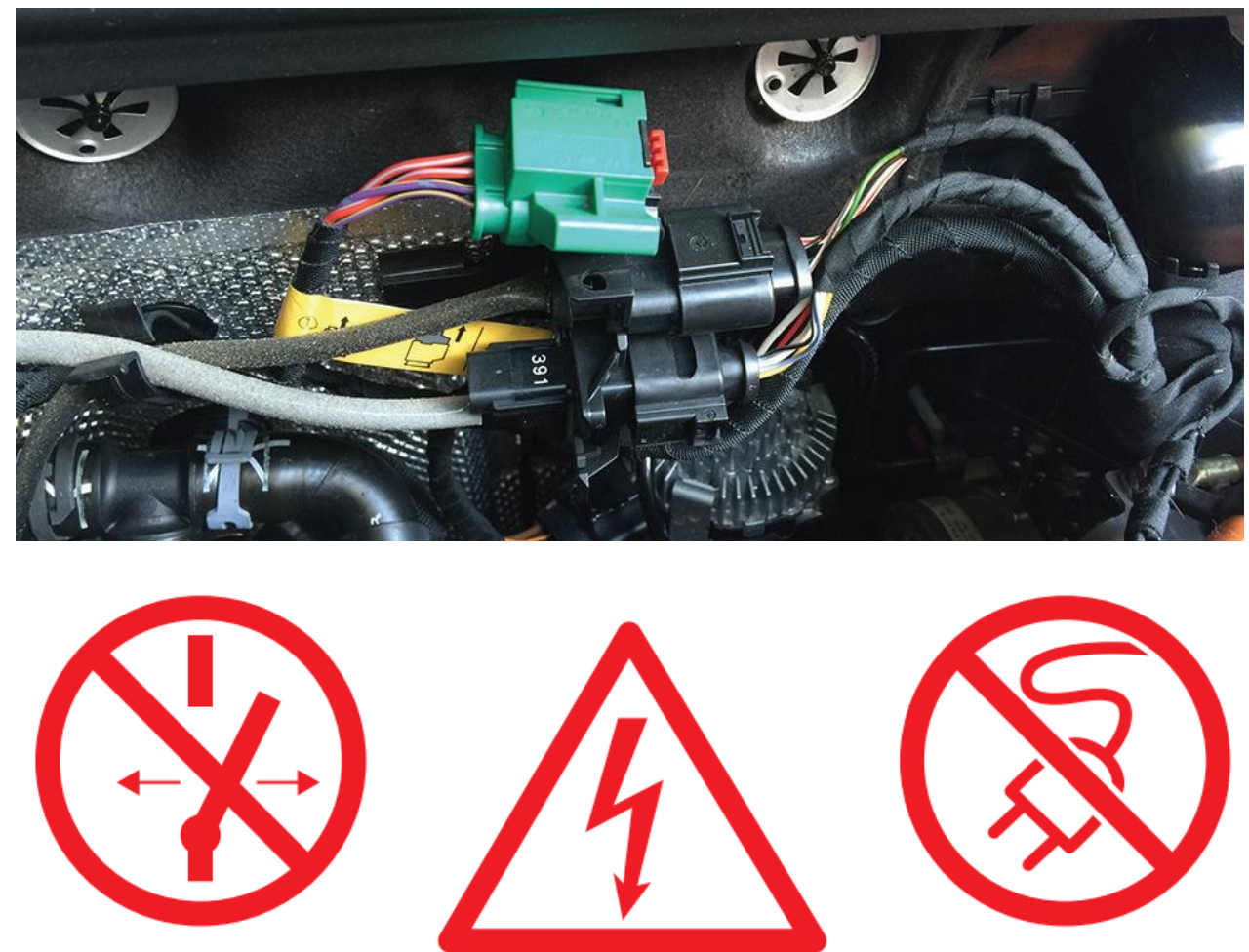

Figure 4. Maintenance connector (green) on a Golf GTE and warning signs used when working on EVs [3]

\subsubsection{Relation Between Other Vehicle Systems}

Working on any of the devices will impact others if caution is not taken. The removal and replacement of any part as basic as an oil filter, for example, will impact certain devices if you unintentionally detach or break the oil pressure switch by slipping with a strap wrench [3].

For this cause, and of course it becomes even more important when dealing with a high-energy device, interfaces to other processes should always be considered. A good example would be if a 12-V battery on a HEV is removed, the high-voltage battery and the DC - DC converter could still power the device. Hence, information from the manufacturers is crucial in situations like this [3].

\subsection{High-Voltage Components}

It is necessary to inspect high voltage parts during any maintenance or repair process. Two main factors to be conscious of when testing high-voltage components are the following: current draw capacity of the vehicle's short circuit potential and possible damage to the vehicle part. You must therefore be able to recognize elements and the methods used to attach them. High-voltage parts and high-voltage wires should be visually inspected for degradation and proper routing, as well as for protection. Pay attention to the followings during visual inspection: any visible defects to the high-voltage elements; faulty or degraded high-voltage cable insulation; any irregular high-voltage cable deformity. Figure 5 shows examples of cable signal labels [3]. 

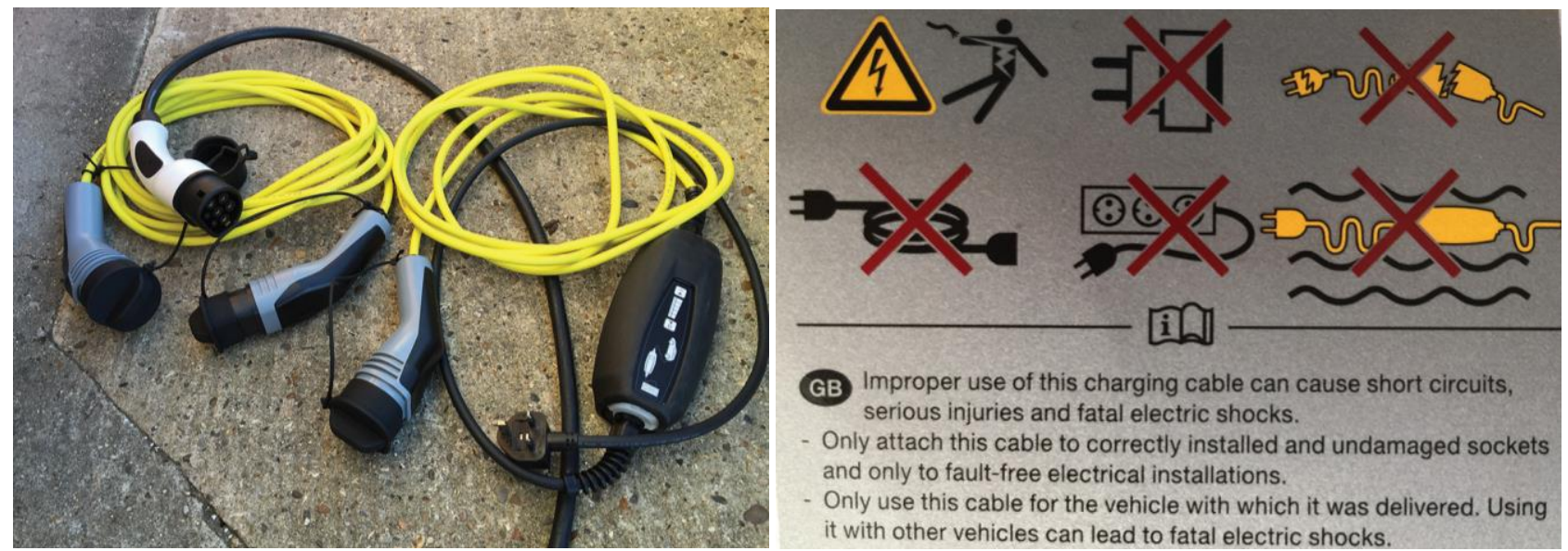

Figure 5. Charging cables and warning information should be checked in the supplied manual [3]

For the battery you should check: Cracks in the upper portion of the battery or battery tray casing; the upper portion of the battery frame or battery tray is deformed; changes in color due to heat and building tarnish. electrolyte leakage; damage to high voltage receptors; fitted labels with legible data; potential line of equalization is fitted; damage from corrosion [3]. Figure 6 illustrate this step.

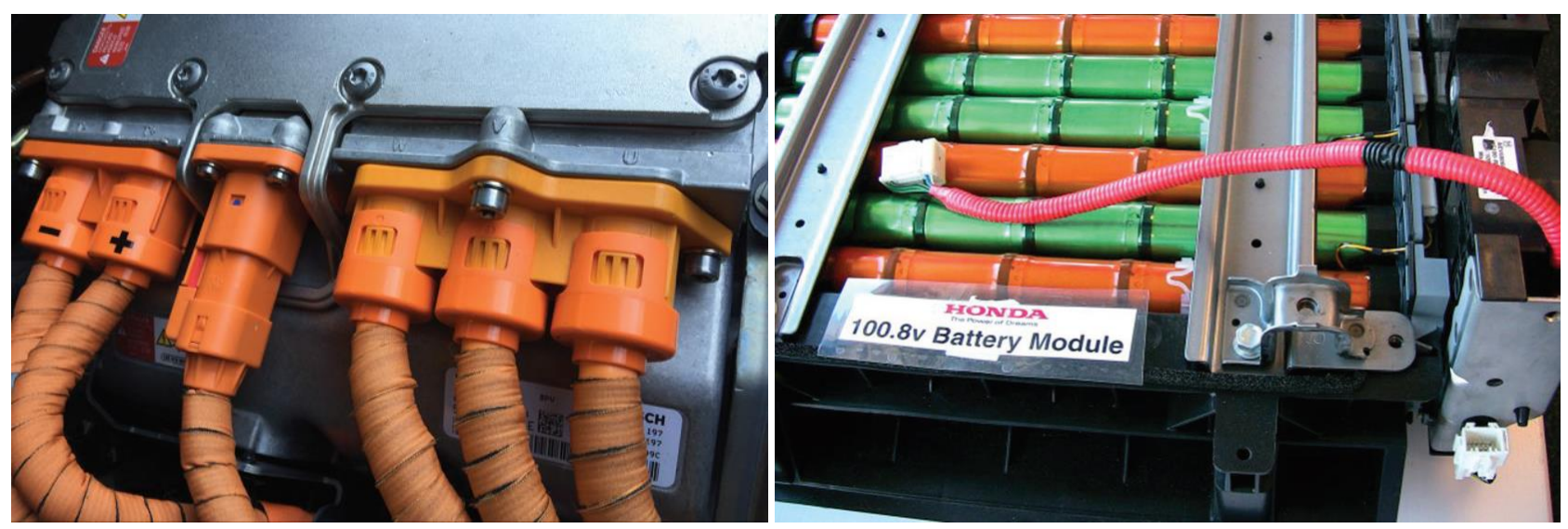

Figure 6. High-voltage cables and Honda battery pack [Source: Honda] [3]

\subsection{Low-Voltage and Other Components}

A major part of our work on EVs would focus on the low voltage networks, as well as high voltage. Often these are defined as 'low-energy' to differentiate elements such as the drive motor from 'high-energy' components - but note that modules such as a starter motor are low-voltage but not low-energy! The low-voltage devices comprise: control units/fuse boxes; low-energy components associated with interior heating; wiring harness/cabling; battery; starter motor; alternator; switches; lighting; lowenergy components associated with air conditioning; alarm/immobilizer; central locking; electric windows/wipers/washers; central locking [3].

Engine compartment region: test the control and power electronics condition for electrical drive, highvoltage cell and air-conditioning compressor cables, high-voltage electrical drive cables and highvoltage charging sockets in radiator grilles or tank caps, as necessary. Underbody: test all high-voltage battery and high-voltage battery cords (Figure 7) [3]. 


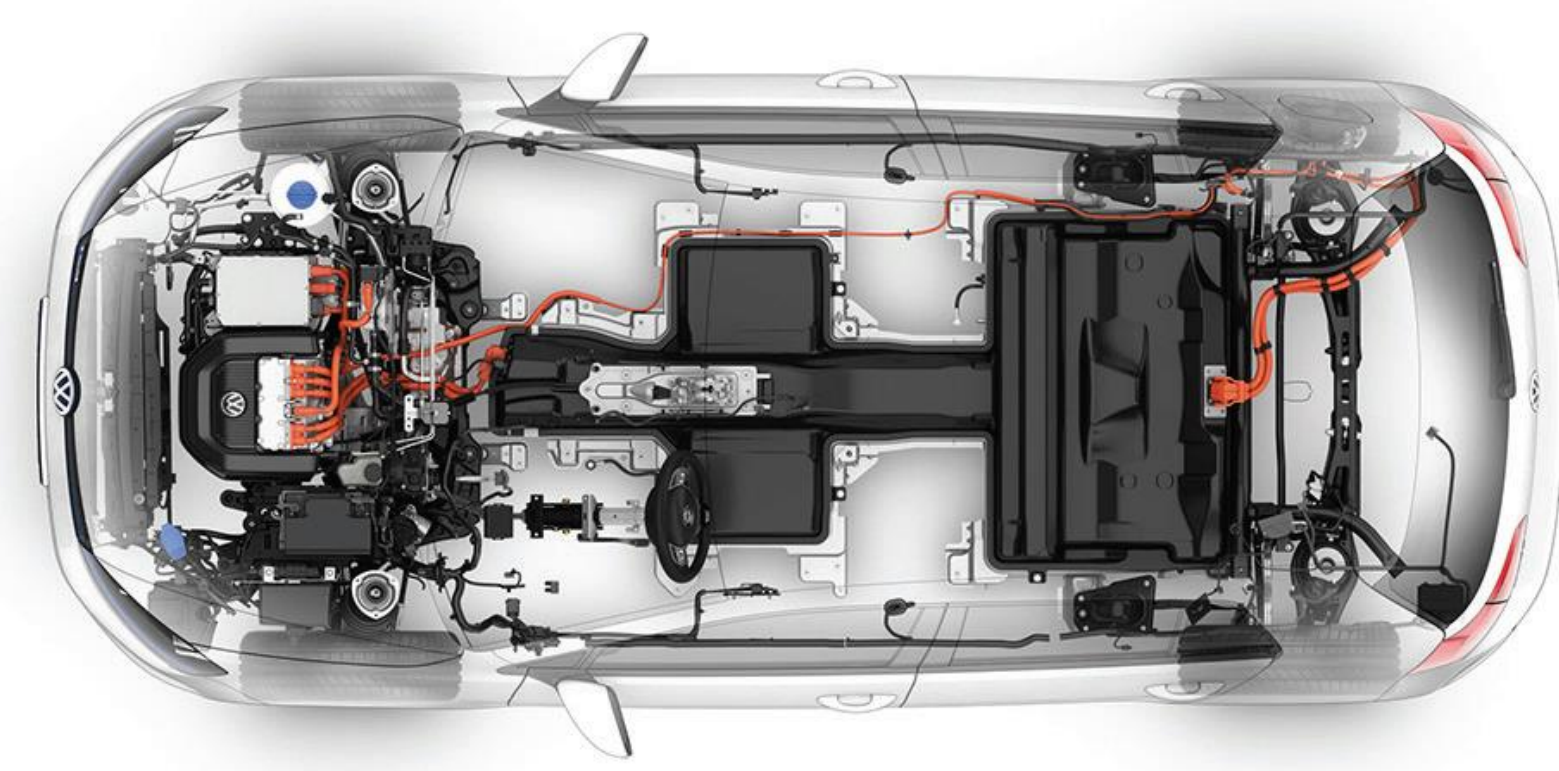

Figure 7. View of the inside components (High-voltage and others) (Source: Volkswagen Media) [3]

\section{Completion of Work}

\subsection{Re-energizing}

After checking the major items pointed in the previous section and running an appropriate verification with your dealership of the vehicle, if no issue was detected or addressed, it is ready for the re-energizing procedures. Major manufacturers provide unique ways of re-energizing the high-voltage device. For this process you need to refer to precise details (given in the manufacturers document). A typical example of a re-energization cycle on a VW car with model year 2015 is provided below: 1. Attach the diagnostic tester; 2. Star the diagnosis by selecting Diagnosis mod and hitting start; 3. Pick the tab on Test schedule; 4. Move Pick your own check button and choose one by one the following menu items:

Body/Electrical system; Self-diagnosis compatible systems; Electric drive control unit; Electric drive control unit, Functions; Re-energize high-voltage system [3].

During the software process of re-energizing you will be required to remove the servicing socket for a high-voltage network. Specific fault codes can request to be tested and/or upgraded, for a correct operation of the driver display module, also the alert information will require a reset [3]. Figure 8 shows an electronic data source used in inspections on dealerships. 


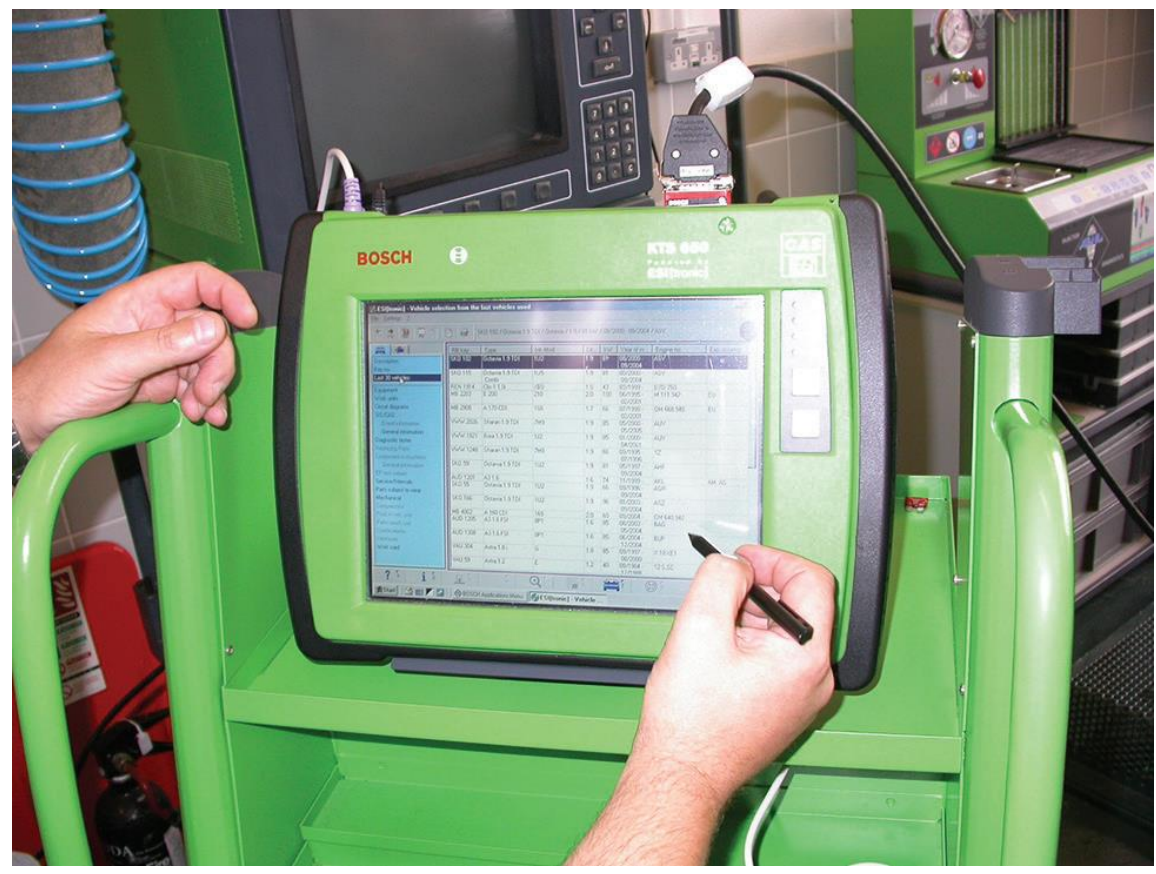

Figure 8. View of the inside components (High-voltage and others) (Source: Volkswagen Media) [3]

\section{Final Words}

As observed, the operations involved in the maintenance of EVs are complex task. This work was inspired by the goal to breakdown, in a simpler form, the major sections of this kind of operation and give a better overview of the EVs as a whole.

\section{References}

[1] I. Husain, Electric and hybrid vehicles: design fundamentals. Boca Raton, Fla.: CRC Press, 2003.

[2] G. Pistoia, Ed., Electric and hybrid vehicles: power sources, models, sustainability, infrastructure and the market. Amsterdam ; Boston: Elsevier, 2010.

[3] T. Denton, Electric and Hybrid vehicles. Milton Park, Abingdon, Oxon ; New York, NY: Routledge, 2016.

[4] A. Emadi, Advanced Electric Drive Vehicles. 2017.

[5] W. Liu, Introduction to hybrid vehicle system modeling and control. Hoboken, N.J: Wiley, 2013.

[6] R. Szabolcsi, Modern Control Engineering. Óbuda University, ISBN 978-963-449-1880, p472, 2019.

[7] R. Szabolcsi, Modern Control System Design and Analysis Using MATLAB, Óbuda University, ISBN 978-963-449-1873, p396, 2020.

[8] Hillside Auto Repair, The Hybrid Specialists: HYBRID BATTERY REPAIR, url: https://www.hillsideautorepair.com/blog/hybrid-battery-repair---do-not-try-this-at-home-, Downloaded.: 2020-07-06 10:43. 